\title{
Mechanical ventilation induces inflammation, lung injury, and extra-pulmonary organ dysfunction in experimental pneumonia
}

\begin{abstract}
Shireesha Dhanireddy ${ }^{1}$, William A Altemeier ${ }^{2}$, Gustavo Matute-Bello ${ }^{2,3}$, D Shane O’Mahony ${ }^{1}$, Robb W Glenny ${ }^{2,4}$, Thomas R Martin ${ }^{2,3}$ and W Conrad Liles ${ }^{1,5,6}$

${ }^{1}$ Division of Allergy and Infectious Diseases, Department of Medicine, University of Washington, Seattle, WA, USA; ${ }^{2}$ Division of Pulmonary and Critical Care Medicine, Department of Medicine, University of Washington, Seattle, WA, USA: ${ }^{3}$ Medical Research Service of the VA Puget Sound Healthcare System, Seattle, WA, USA; ${ }^{4}$ Department of Physiology and Biophysics, University of Washington, Seattle, WA, USA; ${ }^{5}$ Department of Pathology, University of Washington, Seattle, WA, USA and ${ }^{6}$ Department of Medicine, University of Toronto, Toronto, ON, Canada
\end{abstract}

\begin{abstract}
Mechanical ventilation (MV) is frequently employed for the management of critically ill patients with respiratory failure. A major complication of mechanical ventilation (MV) is the development of ventilator-associated pneumonia (VAP), in which Staphylococcus aureus is a prominent pathogen. Moreover, previous studies suggest that MV may be an important cofactor in the development of acute lung injury (ALI) and the acute respiratory distress syndrome (ARDS). S. aureus pulmonary infection was induced in spontaneously breathing mice $(\mathrm{C} 57 \mathrm{BI} / 6)$ or mechanically ventilated mice to determine whether MV contributes to the development of ALI and/or systemic inflammation. The combination of MV and bacteria significantly increased the influx of neutrophils into bronchoalveolar lavage fluid (BALF), augmented pulmonary production of the proinflammatory cytokines KC, MIP-2, TNF- $\alpha$, and IL-6, and increased alveolar-capillary permeability to proteins. MV also induced proinflammatory cytokine expression in peripheral blood, associated with extrapulmonary hepatic and renal dysfunction. Surprisingly, bacterial clearance in the lungs and extrapulmonary bacterial dissemination was not affected by MV. These data indicate that MV exacerbates both pulmonary and systemic inflammation in response to bacteria and contributes to the pathogenesis of both ALI and the multiple organ dysfunction syndrome, without necessarily affecting bacterial clearance or extra-pulmonary bacterial dissemination.
\end{abstract}

Laboratory Investigation (2006) 86, 790-799. doi:10.1038/labinvest.3700440; published online 3 July 2006

Keywords: acute lung injury; inflammation; mechanical ventilation; multiple organ dysfunction syndrome

Mechanical ventilation (MV) is a life-saving intervention for patients with respiratory failure from various underlying problems, including pneumonia, sepsis, and trauma. Ventilator-associated pneumonia (VAP) is a frequent complication of mechanical ventilation and an important cause of morbidity and mortality in critically ill patients. ${ }^{1,2}$ VAP results from oropharyngeal bacterial colonization and subsequent aspiration, develops in up to one-third of mechanically ventilated patients, and is an important risk factor for the development of acute lung

Correspondence: Dr S Dhanireddy, MD, Division of Allergy and Infectious Diseases, Department of Medicine, University of Washington, Box 358050, 815 Mercer Street, Seattle, WA 98103, USA.

E-mail: sdhanir@u.washington.edu

Received 1 February 2006; revised 13 April 2006; accepted 19 April 2006; published online 3 July 2006 injury (ALI) and acute respiratory distress syndrome (ARDS). ${ }^{3}$ A common complication of ALI/ARDS is multiple organ dysfunction syndrome (MODS), which occurs in up to $90 \%$ of patients. ${ }^{4,5}$ MODS, which frequently affects the kidney and liver as evidenced by biochemical markers of injury such as serum creatinine, and alanine aminotransferase (ALT), and aspartate aminotransferase (AST), leads to significant morbidity and mortality in these patients, and is a major risk factor for death in patients with ARDS. ${ }^{5-8}$ Currently, the cellular and molecular mechanisms responsible for the pathogenesis of MODS are unclear.

In the absence of established lung injury, conventional MV strategies employing tidal volumes of $10-12 \mathrm{~mL} / \mathrm{kg}$ are often used for the management of critically ill patients. ${ }^{9}$ However, when bacterial endotoxin is present in the systemic circulation or in the alveolar air spaces, experimental studies have 
shown that MV may contribute to the development of ALI. ${ }^{10-12}$ Whereas experimental models of ALI employing injurious ventilation $(15-21 \mathrm{~mL} / \mathrm{kg}$ ) not commonly used in clinical practice have resulted in the development of MODS, experimental studies with conventional MV in animal models to evaluate distal, extra-pulmonary organ injury have not been performed..$^{8,13}$

We hypothesized that conventional MV leads to an augmented inflammatory response, as well as delayed bacterial clearance in response to pulmonary bacterial infection. To test this hypothesis, we developed a clinically relevant model of either Gram-positive (Staphylococcus aureus, one of the most common bacterial pathogens implicated in VAP) or Gram-negative (Escherichia coli) bacterial infection in mice receiving conventional MV. ${ }^{14,15} \mathrm{In}$ this model, MV augmented both pulmonary and systemic inflammatory responses resulting in acute lung injury and distal organ dysfunction, without affecting bacterial clearance in the lung or extrapulmonary bacterial dissemination. These results demonstrate that conventional MV contributes to the development of ARDS and the progression to MODS via augmentation of both pulmonary and extrapulmonary proinflammatory host responses in bacterial infection.

\section{Materials and methods}

\section{Bacteria}

S. aureus was originally isolated from a patient with catheter-related sepsis, expanded, and stored in frozen aliquots at $-70^{\circ} \mathrm{C} \cdot{ }^{16} 100 \mu \mathrm{l}$ of $S$. aureus from frozen stock was used to seed a $10 \mathrm{ml}$ Trypticase soy (TS) broth (BD Biosciences; Franklin Lakes, NJ, USA) and incubated for 6 -h at $37^{\circ} \mathrm{C}$ in a shaking incubator. Following incubation, $500 \mu \mathrm{l}$ of incubated broth was used to seed $50 \mathrm{ml}$ TS broth, which was then incubated overnight at $37^{\circ} \mathrm{C}$ in a shaking incubator. Broth was spun at $2000 \mathrm{~g}$, and the pellet washed three times and resuspended in $1 \mathrm{ml}$ sterile $0.9 \% \mathrm{NaCl}$. Bacterial concentration of slurry was confirmed using the pour plate method. Viability of the bacterial inoculum was determined by its ability to grow in culture.

E. coli serotype K-1 was originally isolated from a patient with biliary sepsis. Pathogenicity of the bacteria was previously verified in mice and rabbits. ${ }^{16}$ For each experiment, a separate aliquot of bacterial stock was thawed, inoculated into $50 \mathrm{ml}$ LB broth (Sigma; St Louis, MO, USA), and incubated overnight at $37^{\circ} \mathrm{C}$ on a shaking incubator. Bacterial slurry was prepared as described above.

\section{Animal Protocol}

The animal protocol was approved by the Animal Care Committee of the University of Washington
Medical Center. Male C57BL/6 mice weighing 20-30 g were obtained from Jackson Laboratories.

\section{Experimental Design}

Six mice were picked randomly from a cage and assigned on the experimental day to each of following groups: (1) PBS aspiration and spontaneous breathing (PBS); (2) PBS aspiration and MV (MV); (3) bacterial aspiration and spontaneous breathing (S. aureus or E. coli); or (4) bacterial aspiration and MV (S. aureus + MV or E. coli $+\mathrm{MV})$.

Mice were anesthetized with inhaled $4 \%$ isoflurane, and suspended by their front teeth. The instillate was deposited in the oropharynx and the mice returned to their cages for $30 \mathrm{~min} .{ }^{17}$ After $30 \mathrm{~min}$, additional mice were euthanized to determine initial bacterial deposition and lung responses, and the remaining mice were reanesthetized with intraperitoneal ketamine $(1.3 \mathrm{mg})$ and xylazine (0.9 $\mathrm{mg}$ ) followed by $4 \%$ isoflurane. Mice in nonventilated groups were returned to their cages, monitored for recovery from anesthesia, and then allowed free access to food and water. Mice assigned to receive MV were intubated endotracheally as previously described, and ventilated with a tidal volume of $10 \mu \mathrm{l} / \mathrm{g}$ body weight, a respiratory rate of $150 / \mathrm{min}, 0 \mathrm{cmH}_{2} \mathrm{O}$ end-expiratory pressure, and $\mathrm{FiO}_{2}$ of 0.21 , using a rodent ventilator (MiniVent, Harvard Biosciences; Holliston, MA, USA). ${ }^{12}$ In preliminary studies, this ventilation strategy produced normal arterial blood $\mathrm{pH}$ values $(7.36 \pm 0.08$, $n=4)$. MV was continued for either 6 - or $12-\bar{h}$ with anesthesia maintained by $1 \%$ isoflurane. Mixed expired $\mathrm{CO}_{2}$ (Novametrix; Wallingford, CT, USA) and airway pressure were continuously monitored. Body temperature was monitored by rectal thermistor and maintained between 37 and $38^{\circ} \mathrm{C}$ by a heating lamp. Mechanically ventilated mice received hourly fluid boluses of $10 \mu \mathrm{l} / \mathrm{g}$ body weight warm PBS subcutaneously.

All mice successfully intubated survived to the completion of the ventilation period. At the end of the MV period, mice were euthanized by intraperitoneal sodium pentothal and exsanguinated by cardiac puncture. The thorax was opened, the trachea was visualized and cannulated with a 20-gauge catheter, the left hilum was sutured, and the left lung was removed and homogenized in $2 \mathrm{ml}$ of sterile $\mathrm{H}_{2} \mathrm{O}$ with protease inhibitor (Complete, Roche Applied Science; Indianapolis, IN, USA). Lung homogenate was divided into aliquots for further processing. The right lung was lavaged with five separate $0.5-\mathrm{ml}$ aliquots of $0.9 \% \mathrm{NaCl} / 0.6 \mathrm{mM}$ EDTA at $37^{\circ} \mathrm{C}$ and then fixed by intratracheal instillation of $4 \%$ paraformaldehyde at a transpulmonary pressure of $15 \mathrm{cmH}_{2} \mathrm{O}$. The abdomen was then incised, and the spleen was removed and homogenized in $1 \mathrm{ml}$ protease inhibitor solution. One lobe of the liver and the right kidney were then removed and placed in $4 \%$ paraformaldehyde. 


\section{Measurements}

\section{Cell counts}

Total BALF cell counts were performed with a hemacytometer, and differential cell counts were performed on cytospin preparations stained with modified Wright-Giemsa stain (Diff-Quik, American Scientific Products, McGaw Park, IL, USA). Remaining fluid was spun at $1200 \mathrm{~g}$ for $15 \mathrm{~min}$, and supernatant aliquots were stored at $-80^{\circ} \mathrm{C}$.

\section{Myeloperoxidase activity}

Lung homogenate was combined with $2 \times$ myeloperoxidase (MPO) lysis buffer $(50 \mathrm{mM}$ potassium phosphate (dibasic, anhydrous) $\mathrm{pH} 6.0,5 \%$ hexadecyltrimethyl ammonium bromide (Sigma), and $5 \mathrm{mM}$ EDTA), sonicated on ice with four 15-s pulses (Daigger; Vernon Hills, IL, USA), spun at $10000 \mathrm{~g}$, and supernatants stored at $-80^{\circ} \mathrm{C}$. MPO was measured in supernatants by Amplex Red fluorometric assay (Molecular Probes; Eugene, OR, USA) according to the manufacturer's protocol.

\section{Cytokine assays}

Lung homogenate was combined with $20 \times$ cytokine lysis buffer $(0.5 \%$ Triton X-100, $150 \mathrm{mM} \mathrm{NaCl}$, $15 \mathrm{mM}$ Tris, $1 \mathrm{mM}$ CaCl, $1 \mathrm{mM}$ MgCl, pH 7.40), incubated at $4^{\circ} \mathrm{C}$ for $30 \mathrm{~min}$, spun at $10000 \mathrm{~g}$ for $10 \mathrm{~min}$, and supernatant aliquots stored at $-80^{\circ} \mathrm{C}$. Whole blood samples were spun at $1000 \mathrm{~g}$, and supernatant aliquots stored at $-80^{\circ} \mathrm{C}$. Concentrations of MIP-2, mouse GRO homologue (KC), IL-6, TNF- $\alpha$, IL-10 in BALF, lung homogenates, and serum were measured by multiplex immunoassay (Luminex 100; Austin, TX, USA) using mouse Fluorokine MAP assays (R\&D Systems; Minneapolis, MN, USA) according to the manufacturers' protocols. Samples were normalized by volume.

\section{Lung injury}

Lung injury was assessed by determination of alveolar-capillary permeability to IgM as previously described. ${ }^{11}$ IgM (MV 900000$)$ is almost completely excluded from the normal airspace. ${ }^{18}$ IgM concentrations in BALF were determined by using an enzyme-linked immunoassay (Bethyl Laboratories; Inc., Montgomery, TX, USA).

\section{Histology}

Right lungs were fixed at a transpulmonary pressure of $15 \mathrm{cmH}_{2} \mathrm{O}$ with $4 \%$ paraformaldehyde. After fixation, lungs, livers, and kidneys were embedded in paraffin, cut into $4 \mu \mathrm{m}$ sections, and stained with hematoxylin and eosin.

\section{Markers of distal organ dysfunction}

Creatinine, ALT, and AST were measured in serum samples in the clinical laboratory at the University of Washington using standard techniques for assay of clinical specimens.

\section{Bacterial cultures}

Quantitative cultures of lung and spleen homogenates were performed by pour plate method. Colony-forming units (CFU) were counted after $24 \mathrm{~h}$ incubation at $37^{\circ} \mathrm{C}$.

\section{Statistical analysis}

The investigator was not blinded during the experiments; however, cytokine measurements, histology, ELISAs, and other assays were performed in a blinded manner. For all end points, differences among the groups were evaluated by one-way analysis of variance (ANOVA), using Tukey's post hoc analysis. For all statistical tests, a $P$-value $\leq 0.05$ was considered significant. Baseline considered was PBS alone. Results are presented as mean \pm standard error of the mean (s.e.m.). InStat (GraphPad; San Diego, CA, USA) was used for statistical analysis.

\section{Results}

\section{Augments Lung Inflammation and Injury in Bacterial Infection}

\section{Cellular response}

At $6 \mathrm{~h}$, neutrophil counts in BALF from the $S$. aureus $+\mathrm{MV}$ group were greater than in the other groups $\left(S\right.$. aureus $+\mathrm{MV}$ : $0.87 \pm 0.15 \times 10^{6}$ cells; PBS: $0 \pm 0$ cells; MV: $0.01 \pm 0.00 \times 10^{6}$ cells; $S$. aureus: $0.1 \pm 0.06 \times 10^{6}$ cells). Neutrophil counts were further increased in the $S$. aureus $+\mathrm{MV}$ group at $12 \mathrm{-h}$ compared to the other groups $(P<0.05$, Figure 1a). Similarly, total cell counts were greater in the $S$. aureus $+\mathrm{MV}$ group as compared to the other three groups at both 6 and $12 \mathrm{~h}(P<0.05$, Figure $1 \mathrm{~b})$.

MPO activity in lung homogenates was measured to determine neutrophil recruitment to the vascular, parenchymal, and alveolar spaces in the lung. At $6 \mathrm{~h}, \mathrm{MPO}$ activity was significantly greater in the $S$. aureus $+\mathrm{MV}$ group $(16.68 \pm 0.56 \mathrm{AU})$ compared to PBS (1.14 $\pm 0.47 \mathrm{AU}), \mathrm{MV}(6.42 \pm 1.70 \mathrm{AU})$, and $S$. aureus $(5.91 \pm 1.54 \mathrm{AU})(P<0.05$, Figure 1c). At $12 \mathrm{~h}, \mathrm{MPO}$ was not statistically different among the four groups.

\section{Pulmonary cytokine production}

Cytokine concentrations in BALF and lung homogenates were measured at 6 and $12 \mathrm{~h}$. KC concentrations in BALF were significantly greater in the $S$. aureus + MV group $(797.1 \pm 59.1 \mathrm{pg} / \mathrm{ml})$ compared to the other three groups $(P<0.001$, Figure 2a). KC concentrations in lung homogenates were also significantly greater at $6 \mathrm{~h}$ in the $S$. aureus $+\mathrm{MV}$ group $(862.9 \pm 41.3 \mathrm{pg} / \mathrm{ml})$ compared to the other groups $(P<0.05$, Figure $2 \mathrm{~b})$. KC concentrations in both BALF and lung homogenates were also significantly greater at $12 \mathrm{~h}$ compared to the other groups $(P<0.05$, Figure 2a and $\mathrm{b})$.

MIP-2 concentrations in BALF were significantly greater in the $S$. aureus $+\mathrm{MV}$ group at $6 \mathrm{~h}(844.7 \pm$ $97.8 \mathrm{pg} / \mathrm{ml})$ and at $12 \mathrm{~h}(1501.2 \pm 130.9 \mathrm{pg} / \mathrm{ml})$ 

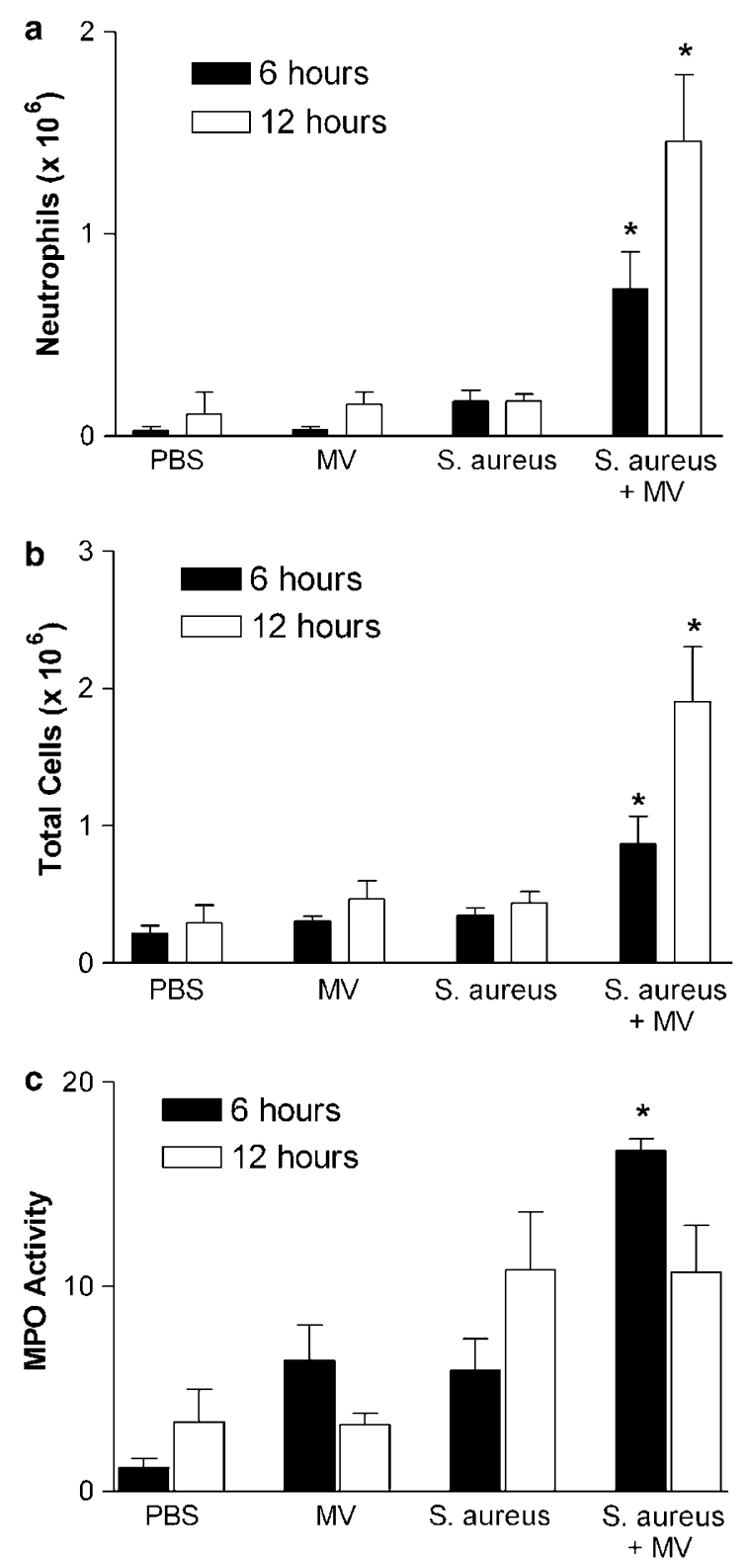

Figure 1 Neutrophil counts in BALF (a); total cell counts in BALF (b); MPO activity in lung homogenates (c). $n=6$ mice/group. $P<0.05$ compared with all three other groups (*), MV-only and control groups (†), and S. aureus-only and control groups (\#).

compared to the other groups $(P<0.05$, Figure 2c). Similarly, in lung homogenates, MIP-2 concentrations were greater in the $S$. aureus $+\mathrm{MV}$ group at $6 \mathrm{~h}$ $(1812.8 \pm 195.9 \mathrm{pg} / \mathrm{ml})$ and $12 \mathrm{~h}(1592.0 \pm 276.6 \mathrm{pg} / \mathrm{ml})$ $(P<0.05$, Figure 2d).

Additionally, the cytokine concentrations of TNF$\alpha$ and IL-6 in both BALF and lung homogenate were greatest in the mice with $S$. aureus infection that received MV (S. aureus + MV; Figure 2e-g).

Cellular and cytokine responses in E. coli infection Neutrophil counts and cytokine concentrations were measured at $6 \mathrm{~h}$ in mice with $E$. coli infection. Neutrophil counts were significantly increased in
BALF from mice that received both $E$. coli and MV compared to the other groups (PBS: 0 cells; MV: $9.4 \pm 2.6 \times 10^{3}$ cells; E. coli: $270.5 \pm 54.3 \times 10^{3}$ cells; E. coli $+\mathrm{MV}: 662.8 \pm 87.9 \times 10^{3}$ cells. Cytokines in BALF and serum were increased in the E. coli $+\mathrm{MV}$ group in a similar pattern observed in the $S$. aureus infection model (data not shown).

Lung injury

Alveolar-epithelial permeability was measured by the presence of murine IgM in the BALF. At $12 \mathrm{~h}$, BALF IgM was significantly increased in the $S$. aureus $+\mathrm{MV}$ group $(281.4 \pm 55.3 \mathrm{ng} / \mathrm{ml})$ compared to the other groups (PBS: $23.5 \pm 5.9 \mathrm{ng} / \mathrm{ml} ; \mathrm{MV}$ : $112.2 \pm 13.8 \mathrm{ng} / \mathrm{ml}$ : and S. aureus: $20.4 \pm 3.3 \mathrm{ng} / \mathrm{ml}$ ) $(P<0.05$, Figure 3$)$. At $6 \mathrm{~h}$, no significant differences in the BALF concentrations of IgM were present.

Increased cellularity, predominantly neutrophils, and fibrin stranding were noted in lungs by light microscopy at $12 \mathrm{~h}$ in mice in the $S$. aureus $+\mathrm{MV}$ group (Figure $4 \mathrm{~d}$ ). Mice in the other groups did not have significant alterations in lung structure by light microscopy.

\section{Augments Systemic Inflammation in Bacterial Pneumonia}

Systemic cytokine production

Serum cytokines were measured at 6 and $12 \mathrm{~h}$. At 6 -h, serum IL-6 concentrations were significantly greater in the $S$. aureus + MV group (2195.5 \pm $463.8 \mathrm{pg} / \mathrm{ml}$ ) compared to the three other groups $(P<0.05$, Figure 5a). Results were similar for IL-6 at $12 \mathrm{~h}$. Serum KC concentrations were also significantly increased in the $S$. aureus $+\mathrm{MV}$ group at $6 \mathrm{~h}(2430.8 \pm 379.1 \mathrm{pg} / \mathrm{ml})$ compared to the PBS $(66.9 \pm 11.9 \mathrm{pg} / \mathrm{ml})$ and $S$. aureus $(566.8 \pm 190.9 \mathrm{pg} / \mathrm{ml})$ groups. At $12 \mathrm{~h}$, serum $\mathrm{KC}$ concentrations were not statistically different (Figure 5b). Similarly, MIP-2 concentrations at 6 -h in the $S$. aureus + MV group $(125.6 \pm 21.6 \mathrm{pg} / \mathrm{ml})$ were significantly increased compared to PBS $(7.5 \pm 1.5 \mathrm{pg} / \mathrm{ml})$ and $S$. aureus $(23.3 \pm 6.5 \mathrm{pg} / \mathrm{ml})$, but not compared to MV $(92.2 \pm$ $19.3 \mathrm{pg} / \mathrm{ml}$ ) (Figure 5c). At $12 \mathrm{~h}$, serum MIP-2 concentrations among the groups were not significantly different.

\section{Promotes Distal, Extra-Pulmonary Organ Dysfunction in Bacterial Infection}

Serum creatinine and ALT were measured as markers of kidney and liver injury, respectively. Serum creatinine concentrations were significantly greater in the mechanically ventilated groups (Figure 6a). ALT concentrations in the $S$. aureus + MV group were significantly greater than in the $S$. aureus alone group $(P<0.05)$ and increased compared to the MV group (Figure 6b). Histological sections of the kidneys and livers did not reveal injury or neutrophil influx (data not shown). 

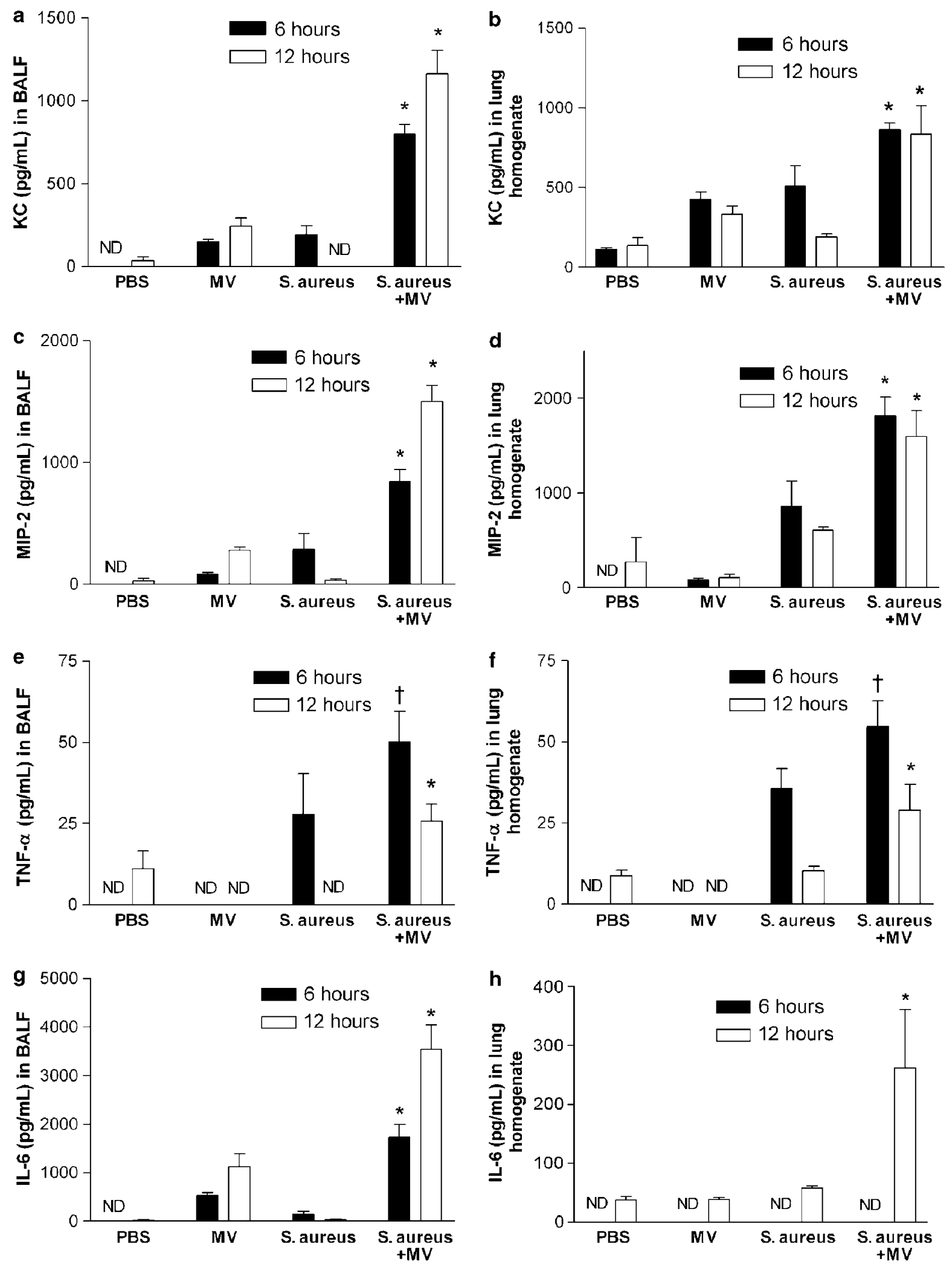

Figure 2 Lung chemokines and cytokines. KC in BALF (a) and lung homogenate (b) and MIP-2 in BALF (c) and lung homogenate (d). TNF- $\alpha$ in BALF (e) and lung homogenate (f). IL-6 in BALF (g) and lung homogenate (h). $n=6$ mice/group. $P<0.05$ compared with all three other groups ( $\left.{ }^{*}\right)$, MV-only and control groups ( $\dagger$ ), and $S$. aureus-only and control groups (\#). None detected (ND)—-the concentration of cytokine was below the limits of detection in the assay ( $\mathrm{KC}<13.0$; MIP- $2<6.86$; TNF- $\alpha<7.13$; IL- $6<8.23$ ). 
MV does not Alter Bacterial Clearance and Dissemination

Bacterial counts were measured from lung homogenates in mice that received $S$. aureus with and without MV. Lung bacterial clearance was rapid and

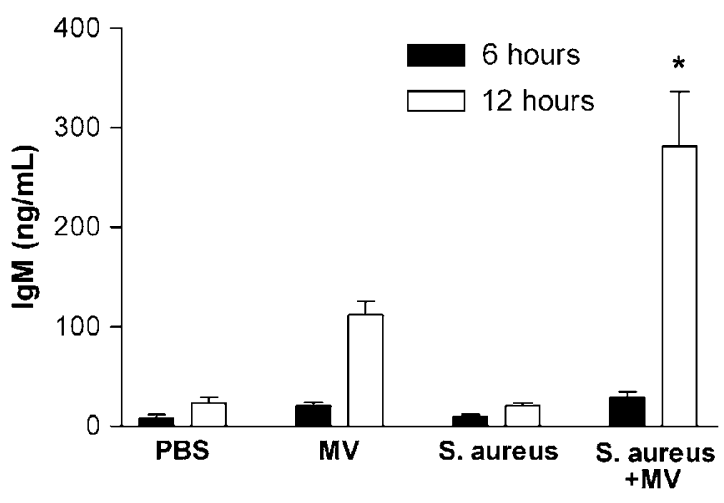

Figure $3 \mathrm{IgM}$ concentration in BALF. $n=6$ mice/group. $P<0.05$ compared with all three other groups $\left(^{*}\right)$, MV-only and control groups ( $\dagger$ ), and $S$. aureus-only and control groups (\#). did not differ at 6 or $12 \mathrm{~h}$ between the groups (Figure $7 a)$. No bacteria were recovered from the spleen at $6 \mathrm{~h}$; however, at $12 \mathrm{~h}$, bacteria were recovered from the spleen, but recovery was not significantly different in the MV group $(451.7 \pm 94.5 \mathrm{CFU})$ compared to the nonventilated group $(241.6 \pm 66.8 \mathrm{CFU})$, (Figure $7 \mathrm{~b})$. Similar results were obtained at $6 \mathrm{~h}$ with the $E$. coli infection groups (data not shown).

\section{Discussion}

The goal of this study was to determine whether MV alters the inflammatory response in a mouse model of pulmonary bacterial infection. We hypothesized that MV augments inflammation and lung injury in bacterial infection. The major findings were that MV not only augments lung inflammation and injury but also systemic inflammation and distal organ dysfunction, without impairment of bacterial clearance. These results validate this murine model as a clinically relevant in vivo experimental system to study the cellular and molecular mechanisms that

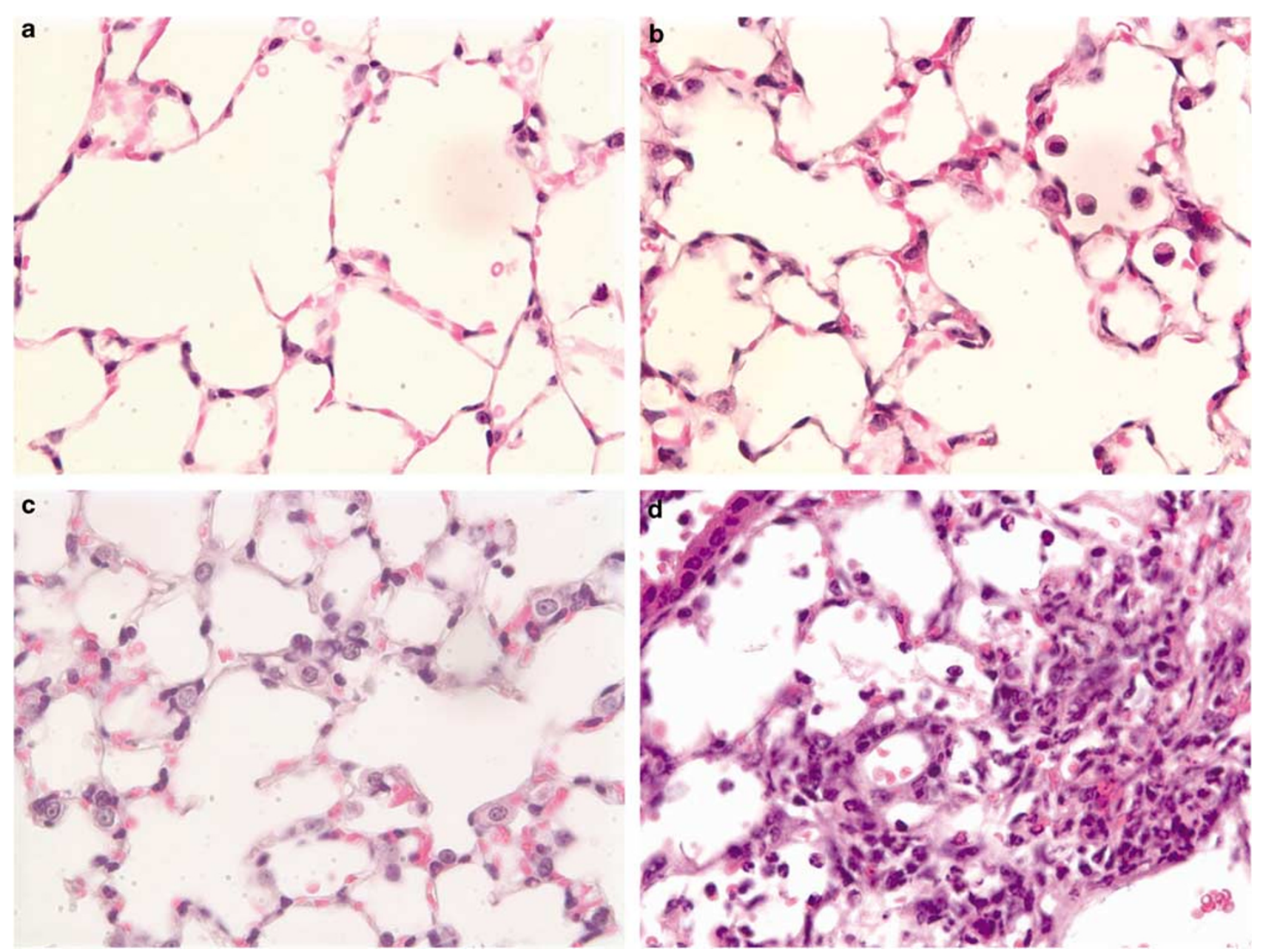

Figure 4 Representative photomicrographs of lung sections from control (a), MV-only (b), S. aureus-only (c), and S. aureus + MV (d) mice at $12 \mathrm{~h}$. Magnification $\times 60$. Panel (d) reveals increased cellularity, predominantly neutrophils, and fibrin stranding in the lung from a mouse in the $S$. aureus + MV group. 

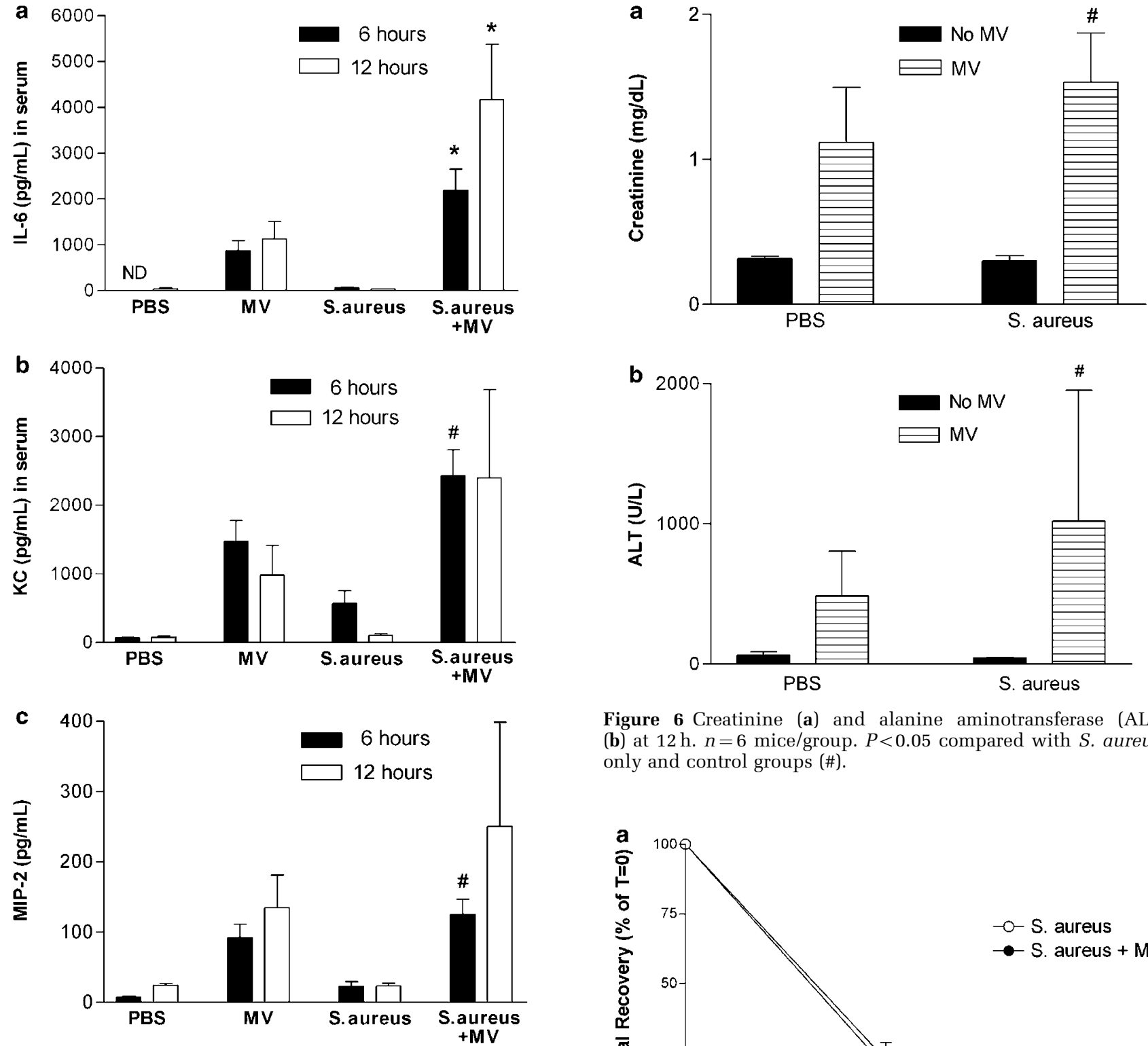

Figure 5 Serum cytokines and chemokines: IL-6 (a); KC (b); MIP-2 (c). $n=6$ mice/group. $P<0.05$ compared with all three other groups (*), MV-only and control groups ( $\dagger$ ), and $S$. aureus-only and control groups (\#). None detected (ND)-the concentration of cytokine was below the limits of detection in the assay (KC $<13.1$; MIP-2 <5.57; IL-6 <8.2).

Figure 6 Creatinine (a) and alanine aminotransferase (ALT) (b) at $12 \mathrm{~h} . n=6$ mice/group. $P<0.05$ compared with $S$. aureusonly and control groups (\#).

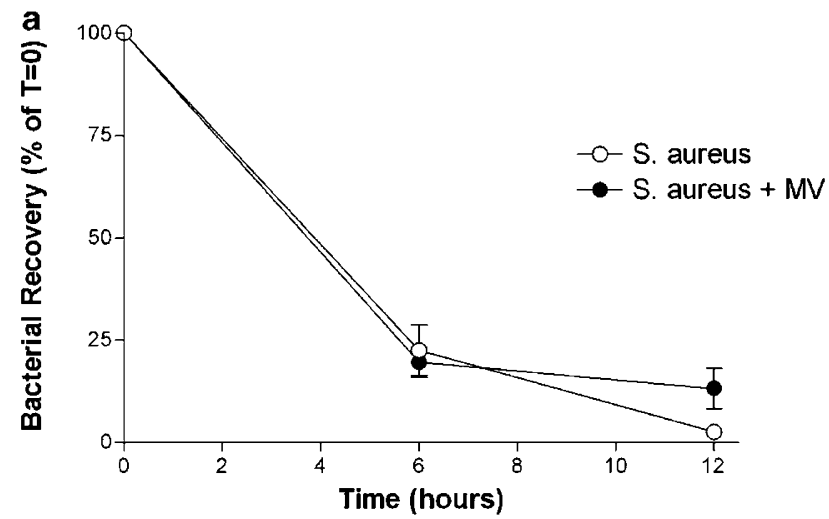

play pathogenic roles in both pneumonia and progression of ALI to MODS.

ALI is an important cause of morbidity and mortality in critically ill patients who receive MV for respiratory failure resulting from a variety of causes, including sepsis, pneumonia, and trauma. ${ }^{19}$ The pathogenesis of ALI, however, remains obscure. MV has been shown to be an important cofactor in the development of ALI. A large randomized clinical trial has shown that MV strategy impacts overall mortality in patients with ARDS. ${ }^{20}$ Specifically, in patients with established ARDS, higher tidal volume ventilation was associated with increased mortality

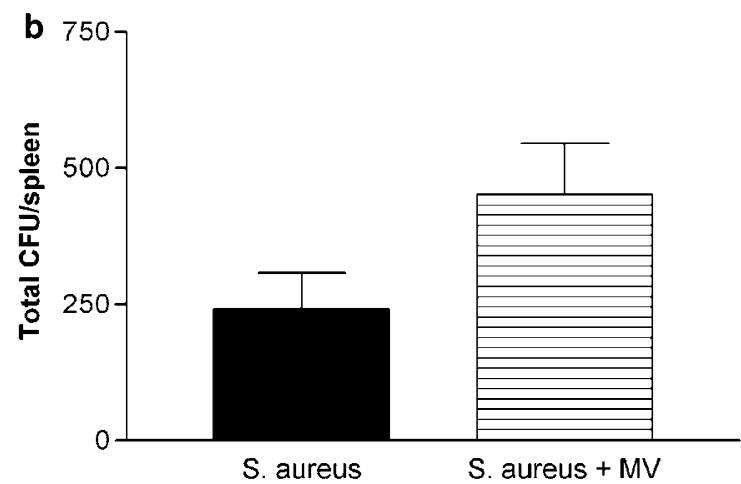

Figure 7 S. aureus quantitative cultures of lung homogenates at 6 and $12 \mathrm{~h}(\mathbf{a})$ and spleen homogenates at $12 \mathrm{~h} \mathrm{(b)}$. 
compared to low tidal volume ventilation. ${ }^{20}$ Mechanically ventilated patients without evidence of ARDS are generally placed on MV with conventional tidal volumes of $10-12 \mathrm{ml} / \mathrm{kg}$. In a recent retrospective study, conventional tidal volume MV in patients without ALI was associated with an increase in development of ALI compared to low tidal volume ventilation. ${ }^{21}$ Determining the role of MV in the development of pneumonia, ALI, and MODS is essential for understanding the pathogenesis of these clinically important disorders.

MV leads to inflammation by altering cellular processes in the lung via mechanical stress. ${ }^{22,23}$ This process generally does not occur in healthy individuals with normal lungs. ${ }^{24,25}$ However, in the setting of previous injury or infection, MV may lead to inflammation and injury of the alveolar epithelial membrane and the development of ALI. ${ }^{10,26}$ Several studies have reported increased levels of proinflammatory cytokines in BALF and serum in patients with ARDS. ${ }^{27-29}$ Previous studies have also shown that MV augments lung inflammation when animals are primed with either systemic or intratracheal endotoxin. ${ }^{10-12}$ Whereas these studies are relevant for patients who aspirate bacterial cell wall products into the lungs, an important question has been the effect of mechanical ventilation in actual bacterial infection.

In this study, the combination of MV and bacterial infection resulted in increased pulmonary and systemic inflammation. Neutrophil counts, MPO activity, and proinflammatory cytokines from BALF and lung parenchyma were all increased with the combination of MV and bacteria. Interestingly, MPO activity in the lung parenchyma was increased at $6 \mathrm{~h}$ in the combination group, but the differences were not significant at $12 \mathrm{~h}$, despite an increase in the number of neutrophils present in the BAL fluid. This decrease in MPO activity at $12 \mathrm{~h}$ may result from diminished neutrophil function as a result of neutrophil apoptosis. ${ }^{30}$

Previous experimental models of bacterial pneumonia have shown that injurious MV $(21 \mathrm{ml} / \mathrm{kg})$ leads to the development of ALI, impairs bacterial clearance, and increases mortality. ${ }^{13}$ However, in the present study, which used conventional tidal volumes, MV did not alter bacterial clearance (Figure 7a). Bacterial clearance was not affected by the addition of mechanical ventilation. The inoculum of bacteria was small, and innate immune defenses in the lung likely cleared the bacteria fairly rapidly. At the 6-h time point, most of the bacteria were cleared. Studies by Skerrett et al have shown that MyD88deficient mice with an attenuated cytokine response to $S$. aureus are still able to effectively clear the organism. ${ }^{31}$ Another recent study found that MV for $4 \mathrm{~h}$ with moderate tidal volumes of $8 \mathrm{ml} / \mathrm{kg}$ did not alter the inflammatory response to Pseudomonas aeruginosa pneumonia. ${ }^{32}$ Shorter time periods of ventilation in that study may not have been sufficient to appreciate the development of lung injury.
The present study also evaluated the systemic inflammatory response to bacterial infection and MV. Serum cytokine concentrations were significantly increased in the $S$. aureus $+\mathrm{MV}$ group (Figures 5a-c). Interestingly, these increases were not associated with impaired bacterial clearance or enhanced bacterial dissemination, suggesting that lung inflammation leads to systemic inflammation by mechanisms other than the direct effects of live bacteria (Figures $7 \mathrm{a}$ and $\mathrm{b}$ ).

An increase in systemic cytokines has been reported both in animal models of lung injury and in humans with ARDS. ${ }^{29,33}$ Bacterial products in the systemic circulation may account for increased serum cytokine concentrations in certain circumstances. ${ }^{34}$ Bacterial components such as peptidoglycan of $S$. aureus and lipopolysaccaride of $E$. coli contribute to the proinflammatory process through initiation of signaling via the toll-like receptor (TLR) pathway. $^{35,36}$ Moreover, MV per se may activate common downstream components of the TLR pathway, such as nuclear factor $\kappa \mathrm{B}(\mathrm{NF}-\kappa \mathrm{B})$ or $\mathrm{c}$-Jun $\mathrm{N}$-terminal kinase (c-JNK), leading to an augmentation in the inflammatory response. ${ }^{37,38}$ Oxidative stress from increased neutrophil activation has also been purposed as a mechanism of systemic inflammation. ${ }^{39}$ Currently, the precise mechanisms responsible for MV-induced proinflammatory responses remain unclear.

Upregulation of inflammatory cytokine responses is thought to be important for the progression of ALI to MODS. ${ }^{40,41}$ MV leads to the release of these inflammatory mediators. Therefore, this study examined not only the production of proinflammatory cytokines but also the effect of MV on extra-pulmonary organ dysfunction. Serum levels of creatinine and ALT, employed as measures of kidney and liver function and/or injury, respectively, were increased in the mechanically ventilated mice (Figure 6a and b). Apoptosis has also been suggested as a mechanism for the development of MODS. ${ }^{42}$ Although a previous study revealed that injurious MV can lead to epithelial cell apoptosis in the kidney as well as organ dysfunction in an animal model, the precise mechanisms involved in the progression of lung injury to extrapulmonary organ dysfunction are currently unknown. ${ }^{7}$

Several issues must be considered when interpreting the results of study. The murine model of lung injury that we have developed results from live bacterial infection and mechanical ventilation. The ventilatory parameters simulate reflect settings used in clinical practice. In mechanically ventilated patients, positive end-expiratory pressure (PEEP) is often used to improve oxygenation, presumably via alveolar recruitment. ${ }^{43}$ PEEP was not used in the experiments performed in the present study; however, subsequent experiments employing $3 \mathrm{cmH}_{2} \mathrm{O}$ PEEP did not significantly alter the observed results (data not shown). We have shown in previous experiments that this MV strategy does not lead independently to inflammation or lung injury. ${ }^{12}$ 
Perhaps most importantly, this murine model provides a clinically relevant in vivo experimental system to study the mechanisms by which MV contributes to the progression of pulmonary bacterial infection to ALI/ARDS and MODS. The development of a murine model simulating the clinical progression from ARDS to MODS is an important advance in the field, which will greatly facilitate detailed studies of the immunopathogenesis of this common clinical scenario in the intensive care unit (ICU). Using this model, we have found that MV with conventional tidal volume augments lung inflammation and injury in bacterial infection without impairing bacterial clearance or promoting bacterial dissemination. Furthermore, the combination of MV and bacterial infection leads to increased systemic inflammation and distal organ injury.

In summary, the results of this study demonstrate that conventional MV can contribute to the pathogenesis of MODS. Understanding the mechanisms that connect lung inflammation and injury to systemic organ dysfunction is fundamentally important for the development of rational strategies for the treatment of sepsis and prevention of its associated complications, such as ALI/ARDS and MODS.

\section{Acknowledgements}

We express our gratitude to Dowon An, Shen-Sheng Wang, Slaid Jones, and Xiaodong Zhu for technical assistance and expertise in the experiments performed for this study. We do not have commercial or other associations that might pose a conflict of interest. This study is supported in part by National Institutes of Health Grants P50 HL073996 and T32 AI007044-29.

\section{References}

1 Chastre J, Fagon JY. Ventilator-associated pneumonia. Am J Resp Crit Care Med 2002;165:867-903.

2 Torres A, Aznar R, Gatell JM, et al. Incidence, risk, and prognosis factors of nosocomial pneumonia in mechanically ventilated patients. Am Rev Resp Dis 1990;142:523-528.

3 Dreyfuss D, Ricard JD. Acute lung injury and bacterial infection. Clin Chest Med 2005;26:105-112.

4 Cocanour CS, Ostrosky-Zeichner L, Peninger M, et al. Cost of a ventilator-associated pneumonia in a shock trauma intensive care unit. Surg Infect (Larchmt) 2005; 6:65-72.

5 Brun-Buisson C, Minelli C, Bertolini G, et al. Epidemiology and outcome of acute lung injury in European intensive care units. Results from the ALIVE study. Intens Care Med 2004;30:51-61.

6 Lefering R, Goris RJ, van Nieuwenhoven EJ, et al. Revision of the multiple organ failure score. Langenbecks Arch Surg 2002;387:14-20.

7 Vincent JL, Sakr Y, Ranieri VM. Epidemiology and outcome of acute respiratory failure in intensive care unit patients. Crit Care Med 2003;31:S296-S299.
8 Imai Y, Parodo J, Kajikawa O, et al. Injurious mechanical ventilation and end-organ epithelial cell apoptosis and organ dysfunction in an experimental model of acute respiratory distress syndrome. JAMA 2003; 289:2104-2112.

9 Pontoppidan H, Geffin B, Lowenstein E. Acute respiratory failure in the adult. 3. N Engl J Med 1972;287: 799-806.

10 Altemeier WA, Matute-Bello G, Frevert CW, et al. Mechanical ventilation with moderate tidal volumes synergistically increases lung cytokine response to systemic endotoxin. Am J Physiol Lung Cell Mol Physiol 2004;287:L533-L542.

11 Bregeon F, Delpierre S, Chetaille B, et al. Mechanical ventilation affects lung function and cytokine production in an experimental model of endotoxemia. Anesthesiology 2005;102:331-339.

12 Altemeier WA, Matute-Bello G, Gharib SA, et al. Modulation of lipopolysaccharide-induced gene transcription and promotion of lung injury by mechanical ventilation. J Immunol 2005;175:3369-3376.

13 Lin CY, Zhang $\mathrm{H}$, Cheng KC, et al. Mechanical ventilation may increase susceptibility to the development of bacteremia. Crit Care Med 2003;31:14291434.

14 Vincent JL, Bihari DJ, Suter PM, et al. The prevalence of nosocomial infection in intensive care units in Europe. Results of the European Prevalence of Infection in Intensive Care (EPIC) Study. EPIC International Advisory Committee. JAMA 1995;274:639-644.

15 Gastmeier P, Sohr D, Geffers C, et al. Mortality risk factors with nosocomial Staphylococcus aureus infections in intensive care units: results from the German Nosocomial Infection Surveillance System (KISS). Infection 2005;33:50-55.

16 Matute-Bello G, Frevert CW, Liles WC, et al. Fas/Fas ligand system mediates epithelial injury, but not pulmonary host defenses, in response to inhaled bacteria. Infect Immun 2001;69:5768-5776.

17 Foster WM, Walters DM, Longphre M, et al. Methodology for the measurement of mucociliary function in the mouse by scintigraphy. J Appl Physiol 2001;90: 1111-1117.

18 Holter JF, Weiland JE, Pacht ER, et al. Protein permeability in the adult respiratory distress syndrome. Loss of size selectivity of the alveolar epithelium. J Clin Invest 1986;78:1513-1522.

19 Ware LB, Matthay MA. The acute respiratory distress syndrome. N Engl J Med 2000;342:1334-1349.

20 The Acute Respiratory Distress Syndrome Network. Ventilation with lower tidal volumes as compared with traditional tidal volumes for acute lung injury and the acute respiratory distress syndrome. N Engl J Med 2000;342:1301-1308.

21 Gajic O, Dara SI, Mendez JL, et al. Ventilator-associated lung injury in patients without acute lung injury at the onset of mechanical ventilation. Crit Care Med 2004; 32:1817-1824.

22 Hammerschmidt S, Kuhn $\mathrm{H}$, Grasenack $\mathrm{T}$, et al. Apoptosis and necrosis induced by cyclic mechanical stretching in alveolar type II cells. Am J Resp Cell Mol Biol 2004;30:396-402.

23 Pugin J, Dunn I, Jolliet P, et al. Activation of human macrophages by mechanical ventilation in vitro. Am J Physiol 1998;275:L1040-L1050.

24 Padman R, Alexander M, Thorogood C, et al. Respiratory management of pediatric patients with spinal cord 
injuries: retrospective review of the duPont experience. Neurorehabil Neural Repair 2003;17:32-36.

25 Wrigge H, Uhlig U, Zinserling J, et al. The effects of different ventilatory settings on pulmonary and systemic inflammatory responses during major surgery. Anesth Analg 2004;98:775-781.

26 Frank JA, Gutierrez JA, Jones KD, et al. Low tidal volume reduces epithelial and endothelial injury in acid-injured rat lungs. Am J Resp Crit Care Med 2002;165:242-249.

27 Suter PM, Suter S, Girardin E, et al. High bronchoalveolar levels of tumor necrosis factor and its inhibitors, interleukin-1, interferon, and elastase, in patients with adult respiratory distress syndrome after trauma, shock, or sepsis. Am Rev Resp Dis 1992; 145:1016-1022.

28 Park WY, Goodman RB, Steinberg KP, et al. Cytokine balance in the lungs of patients with acute respiratory distress syndrome. Am J Resp Crit Care Med 2001;164: 1896-1903.

29 Ranieri VM, Suter PM, Tortorella C, et al. Effect of mechanical ventilation on inflammatory mediators in patients with acute respiratory distress syndrome: a randomized controlled trial. JAMA 1999;282:54-61.

30 Matute-Bello G, Martin TR. Science review: apoptosis in acute lung injury. Crit Care 2003;7:355-358.

31 Skerrett SJ, Liggitt HD, Hajjar AM, et al. Cutting edge: myeloid differentiation factor 88 is essential for pulmonary host defense against Pseudomonas aeruginosa but not Staphylococcus aureus. J Immunol 2004; 172:3377-3381.

32 Brackenbury AM, McCaig LA, Yao LJ, et al. Host response to intratracheally instilled bacteria in ventilated and nonventilated rats. Crit Care Med 2004;32: 2502-2507.

33 Chiumello D, Pristine G, Slutsky AS. Mechanical ventilation affects local and systemic cytokines in an animal model of acute respiratory distress syndrome. Am J Resp Crit Care Med 1999;160:109-116.

34 Wang JE, Dahle MK, Yndestad A, et al. Peptidoglycan of Staphylococcus aureus causes inflammation and organ injury in the rat. Crit Care Med 2004;32:546-552.

35 Yoshimura A, Lien E, Ingalls RR, et al. Cutting edge: recognition of gram-positive bacterial cell wall components by the innate immune system occurs via Toll-like receptor 2. J Immunol 1999;163:1-5.

36 Takeuchi O, Hoshino K, Kawai T, et al. Differential roles of TLR2 and TLR4 in recognition of gramnegative and gram-positive bacterial cell wall components. Immunity 1999;11:443-451.

37 Li LF, Yu L, Quinn DA. Ventilation-induced neutrophil infiltration depends on c-Jun N-terminal kinase. Am J Resp Crit Care Med 2004;169:518-524.

38 Held HD, Boettcher S, Hamann L, et al. Ventilationinduced chemokine and cytokine release is associated with activation of nuclear factor-kappaB and is blocked by steroids. Am J Resp Crit Care Med 2001; 163:711-716.

39 Goode HF, Cowley HC, Walker BE, et al. Decreased antioxidant status and increased lipid peroxidation in patients with septic shock and secondary organ dysfunction. Crit Care Med 1995;23:646-651.

40 Schrier RW, Wang W. Acute renal failure and sepsis. N Engl J Med 2004;351:159-169.

41 Haitsma JJ, Uhlig S, Goggel R, et al. Ventilator-induced lung injury leads to loss of alveolar and systemic compartmentalization of tumor necrosis factor-alpha. Intens Care Med 2000;26:1515-1522.

42 Wesche DE, Lomas-Neira JL, Perl M, et al. Leukocyte apoptosis and its significance in sepsis and shock. J Leukoc Biol 2005;78:325-337.

43 Falke KJ, Pontoppidan H, Kumar A, et al. Ventilation with end-expiratory pressure in acute lung disease. J Clin Invest 1972;51:2315-2323. 